\title{
Ground shock attenuation on a buried cylindrical structure by a barrier
}

\author{
Sylwester Kobielak ${ }^{\mathrm{a}, *}$, Theodor Krauthammer ${ }^{\mathrm{b}}$ and Adam Walczak ${ }^{\mathrm{c}}$ \\ ${ }^{a}$ Institute of Building Engineering, Wroctaw University of Technology, 27 Wybrzeze Wyspianskiego, 50-370 \\ Wroclaw, Poland \\ ${ }^{\mathrm{b}}$ Protective Technology Center, Penn State University, 3127 Research Drive, Cato Park, State College, PA 16801, \\ USA \\ ${ }^{\mathrm{c}}$ College of Military Engineering, 100 Czajkowskiego Street, 51-150 Wroctaw, Poland
}

Received 18 August 2005

Revised 8 March 2006

\begin{abstract}
This paper presents results from studies on the influence of an attenuation barrier on soil stresses and pressures acting on a buried silo, caused by underground explosions at different distances from the structure. The attenuation barrier was made of PVC tubes that were placed between the explosive charges and the RC silo structure. Soil stress gages and pressure transducers were used to measure these data in the soil and on the structure, respectively. The influences of several parameters were analyzed for tests with and without an attenuation barrier between the silo and the explosive sources.
\end{abstract}

Keywords: Test, buried cylindrical structure, attenuation barrier, soil, ground shock, pressure, measurement

\section{Introduction}

Only a few studies have been published on protecting underground structures from ground shock induced by buried explosions [6,9]. Buried structures, or buried parts of above-ground structures, may be exposed to such ground shock during wartime, terrorist activities and tunneling during subway construction with drill-and-blast technique activities, as well as drill shaft for transmission line pole foundations activities. Accidental explosions of subterranean gas pipelines or tanks could induce similar effects. Protective barriers (screens) may contribute to decrease such effects to acceptable levels. Following types of barriers can be considered for such applications $[14,17,18]$.

a) Barriers with a low acoustic impedance (LAI), e.g., polyester, styrofoam, etc.

b) Stiff barriers e.g., reinforced concrete (RC),

c) Barriers made of particular media.

d) Gas cushions barriers

One must differentiate between the following two basic types of loading conditions that can occur during an underground explosion in order to evaluate particular barriers [17].

1. Shock loading generated by the stress wave from the blast, as it passes through the soil.

2. Inertial loading resulting from the physical movement of the block of soil located between the detonating charge and the structure.

\footnotetext{
${ }^{*}$ Corresponding author. Tel.: +4871 320 3721; Fax: +4871 322 1465; E-mail: sylwester.kobielak@pwr.wroc.pl.
} 
Table 1

$C_{t}$ coefficient values for different barrier types [17]

\begin{tabular}{cc}
\hline Barrier type & $C_{t}$ \\
\hline Particulate & 0.001 \\
LAI & 0.020 \\
Rigid & 0.107 \\
\hline
\end{tabular}

The PVC barrier is characterized by its considerable shock load attenuation ability. A stiff barrier, in turn, can attenuate inertial loading substantially. Combinations of various types of barriers (e.g., layered polyester-particulate media-polyester) have also been utilized. The attenuation results of such barriers may be found in the work of Williams et al. [17]. To this end, they used a simplified formula to define the degree of attenuation (transmission coefficient) [8]:

$$
C_{t}=\frac{I_{T}}{I_{t}}
$$

Where: $I_{T}$ is the intensity of the waves transmitted through the barrier, and $I_{t}$ is the intensity of incident waves on the barrier. The intensity of waves is defined by the relationship $I=\sigma_{\max }^{2} / \rho \cdot c$ in which $\sigma_{\max }$ is the peak pressure, $\rho$ is the medium density, and $c$ is the wave propagation velocity. They showed that the above noted barrier types contribute to a decrease in the maximum stress levels. The greatest attenuation was attained when particulate and combined barriers were used. The smallest attenuation occurred when reinforced concrete barriers were used. The value of the attenuation coefficient $C_{t}$ is shown in Table 1.

Woods [18], in turn, investigated the influence of an air-gap (i.e., trench type) barrier on the reduction of vibrations. The first scientific investigations on the barrier effect of trench type at large scale were reported by Barkan [2]. Woods at al. [19] studied also the effectiveness of barrier made of rows of discrete cylindrical voids (piles). According to Woods [18] (see [7]) a barrier can be considered as either active isolation or passive isolation. Active isolation is in the case where the barrier completely or partially surrounds the source of vibration continuously (for example circular open trench, Fig. 1a). Passive isolation appears in the case of trench segments (Fig. 1b), and discrete cylindrical voids or holes (piles, Fig. 2b). Woods concluded from the field investigations on passive isolation (e.g., an open trench barrier of depth $H$, length $L$, width $W$, Fig. 2a) that the reduction in the applied vertical vibrations induced through an exciter footings resting at the ground level may be summarized, as follows: For a satisfactory passive isolation (for $R=\lambda_{r}$ to about $7 \lambda_{r}$ ), the minimum trench depth $H$ should be between about 1.2 and $1.5 \lambda_{r}$ and $H / \lambda_{r}$ should be about 1.33, where $\lambda_{r}$ is the wavelength of the Rayleigh waves. One should point out that most of the vibratory energy affecting nearby structures in that case is carried by Rayleigh (surface) waves traveling from the source of vibration. Woods et al. [19] also carried out model tests of passive isolation using both single and double rows of cylindrical holes as an energy barrier. These tests were performed in a box filled with a fine-sand medium (Fig. 2b). Based on these test results they suggested that a row of cylindrical holes may act as an isolation barrier if

$$
D / \lambda_{r} \geqslant 1 / 6
$$

and,

$$
S_{n} / \lambda_{r}<1 / 4
$$

where,

$D$ is the diameter of the cylindrical void, and

$S_{n}$ is the net space for the energy to penetrate between two consecutive void obstacles.

The literature comprises many theoretical investigations regarding the efficiency of vibration isolation barriers, using the Finite Element Method and Boundary Element Method [1,3,4,10]. For a discussion on these investigations, reference is made to Haupt [11] and Massarsch [14].

This paper presents results reduction of soil pressures acting the interface between a RC silo structure and soil as well as of stresses within soil by PVC tubes (passive isolation) placed between buried explosive charges and the buried structure. 

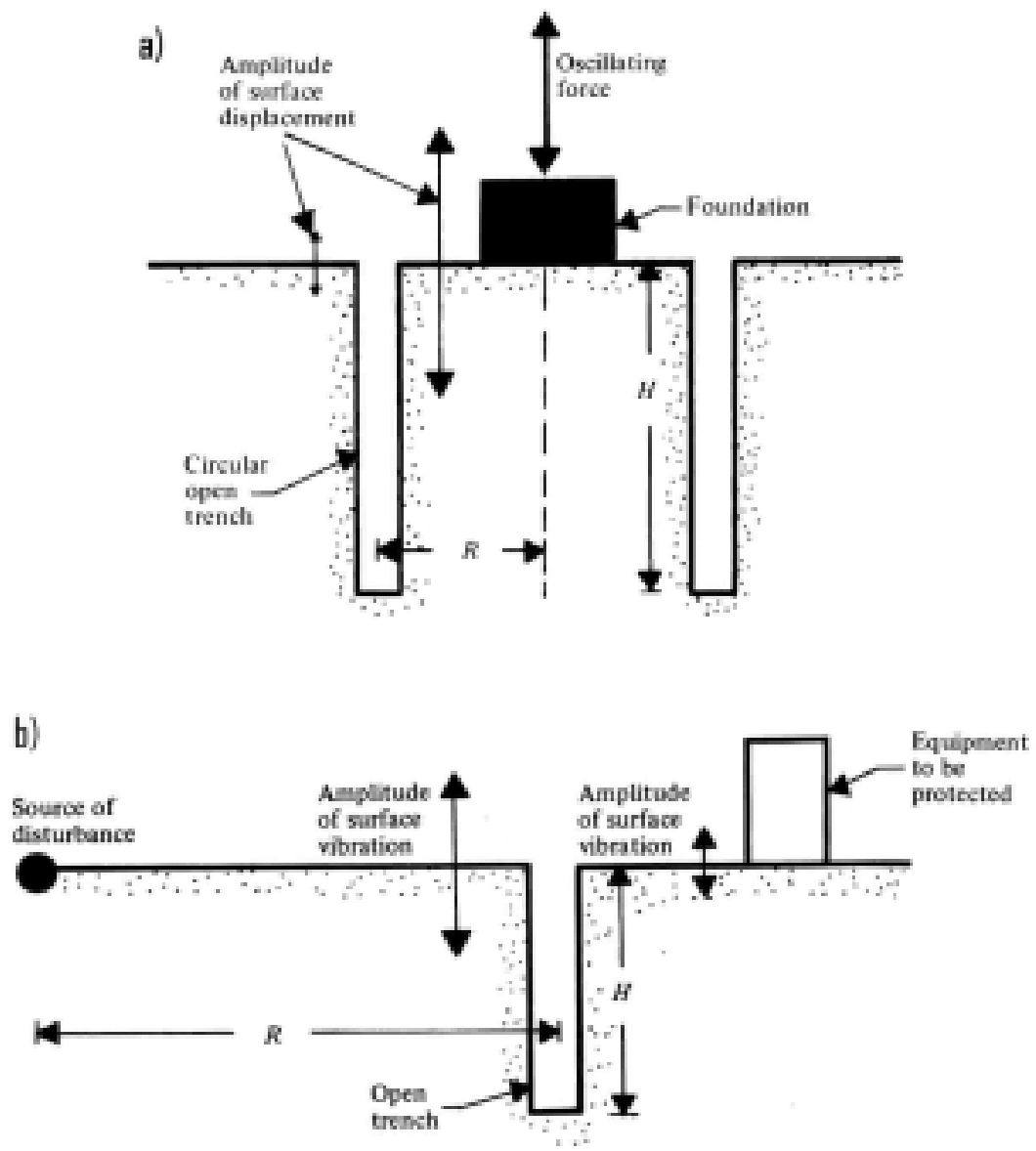

Fig. 1. Active and passive isolation by adequately using (a) a circular open trench, and (b) segment open trench [7,19].

\section{Tests program and site}

Five PVC tubes with a $100 \mathrm{~mm}$. diameter and $2.0 \mathrm{~m}$. length were placed in the soil at $1.0 \mathrm{~m}$. from external surface of a RC cylindrical silo. The empty tubes were located in the three layered soil so that they shielded (protected) the silo structure ( $D=1.78 \mathrm{~m}$ - external diameter and $H=3.40 \mathrm{~m}$ - height) from the ground shock (Fig. 3). The influence of the attenuation barrier on the reduction of stresses $\sigma_{h}$ inside the soil, measured by soil stress gages and the horizontal soil pressure $p_{h}$ acting on the external surface of the silo wall measured by pressure gages, were the subject of study. The influence of distance $R$ and equivalent mass $W_{\text {TNT }}$ of charges in the tests of these quantities were analysed. The depths of charges installation $h$ were the same in all tests. The accelerations $g$ of top point of silo were also measured. The full program of six tests is presented in Fig. 4. The field test scheme with the buried concrete silo structure, arrangements of pressure gages fixed to the wall on $z$ depths and soil stress gages and data acquisition are given on Fig. 5. Figure 5 also shows the position PVC tubes screen as well as charges and the sequence of their explosion denoted by numbers $1 \div 6$. It should be noted that the soil (Fig. 3 ) was undisturbed only in the first test, and its properties are given in [13].

The following parameters are introduced to enable using the presented results and their analyses for determining the blast-induced pressure acting on the silo wall for other sizes but similar structures in which all dimensionless similarity parameters $\pi_{1}, \pi_{2}, \pi_{3}, \ldots, \pi_{13}$ from Eq. (1) are satisfied [13]:

$-\psi\left(\pi_{1}, \pi_{2}, \pi_{3}, \ldots, \pi_{13}\right)=\frac{p_{h}}{\gamma_{s} D}$ - represents the horizontal pressure $p_{h}$ acting on the external surface of silo wall,

$-\pi_{1}=R / D$ - represents the distance $\mathrm{R}$ from the charge to the front of silo wall, 

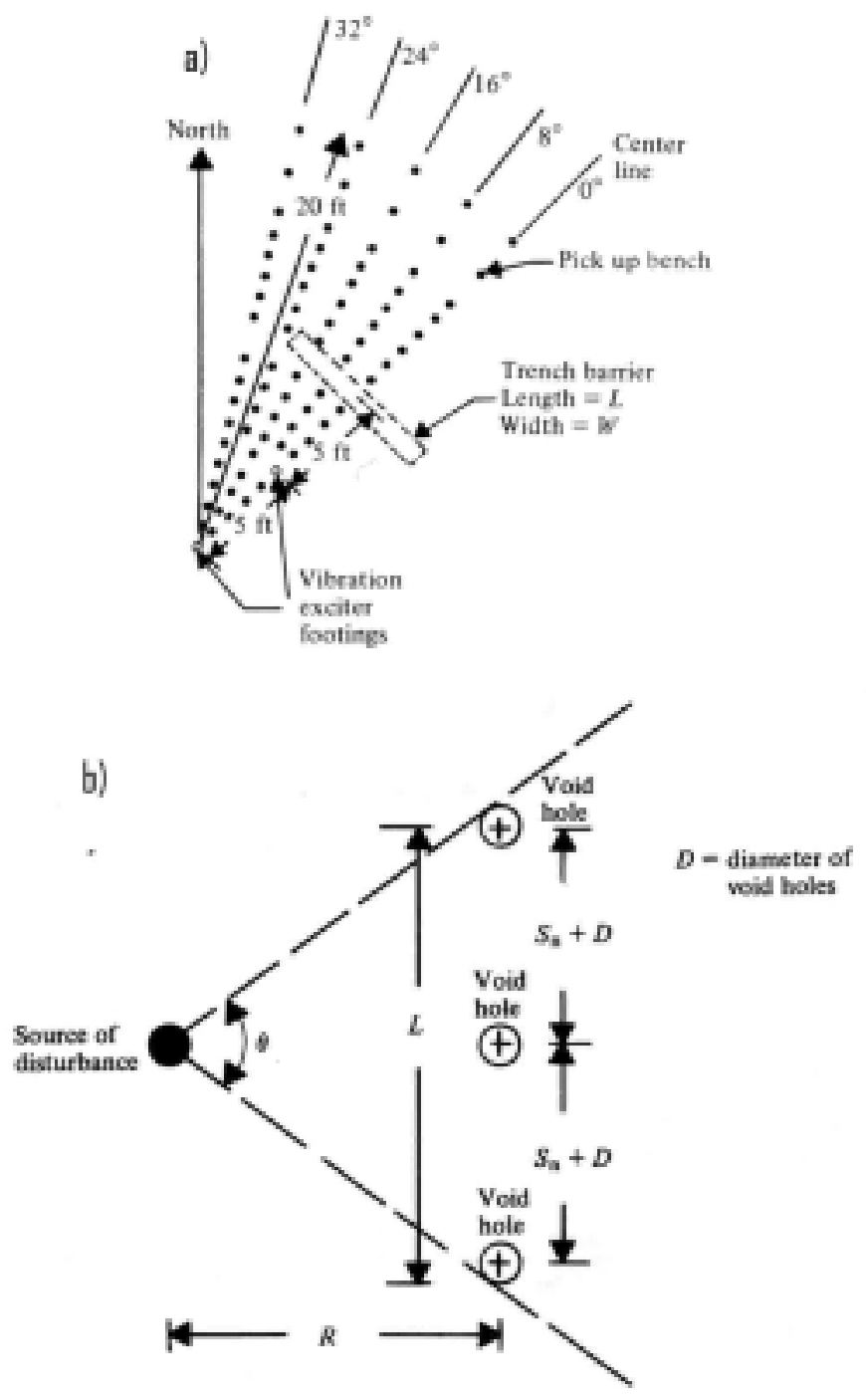

Fig. 2. Passive isolation tests, the plan view of (a) field site, and (b) the model half-space in a box of layouts in $[18,19]$.

- $\pi_{2}=H / D$ - represent silo geometry,

$-\pi_{3}=h / D$ - represents the burial depth of the charge,

$-\pi_{4}=z / D-$ represents the depth at which the pressure is measured,

$-\pi_{6}=\frac{W_{\mathrm{TNT}}}{\gamma_{S} D^{3}}-$ is the scaled mass of the charge

where

$\gamma_{s}=\rho_{s} g-$ specific soil density, $\rho_{d}-$ soil particle density,

$z$-depth at which pressure is measured (see Fig. 5).

\section{Soil stresses}

The stress measurements in the horizontal direction within the soil were made by means of a disk shape soil stress gages with a flexible epoxy external ring (Fig. 6) for reducing the gage cross-sensitivity and the overall unit weight $[5,12]$. Soil stress gages and charges were dropped into previously prepared $1.8 \mathrm{~m}$ deep bore holes. The 


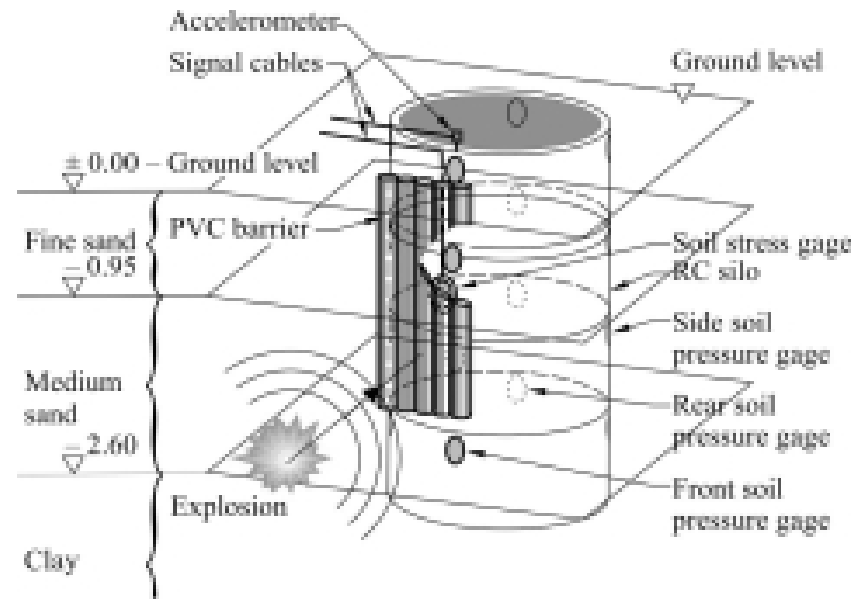

Fig. 3. Configuration scheme of buried RC cylindrical silo with a PVC pipes barrier.

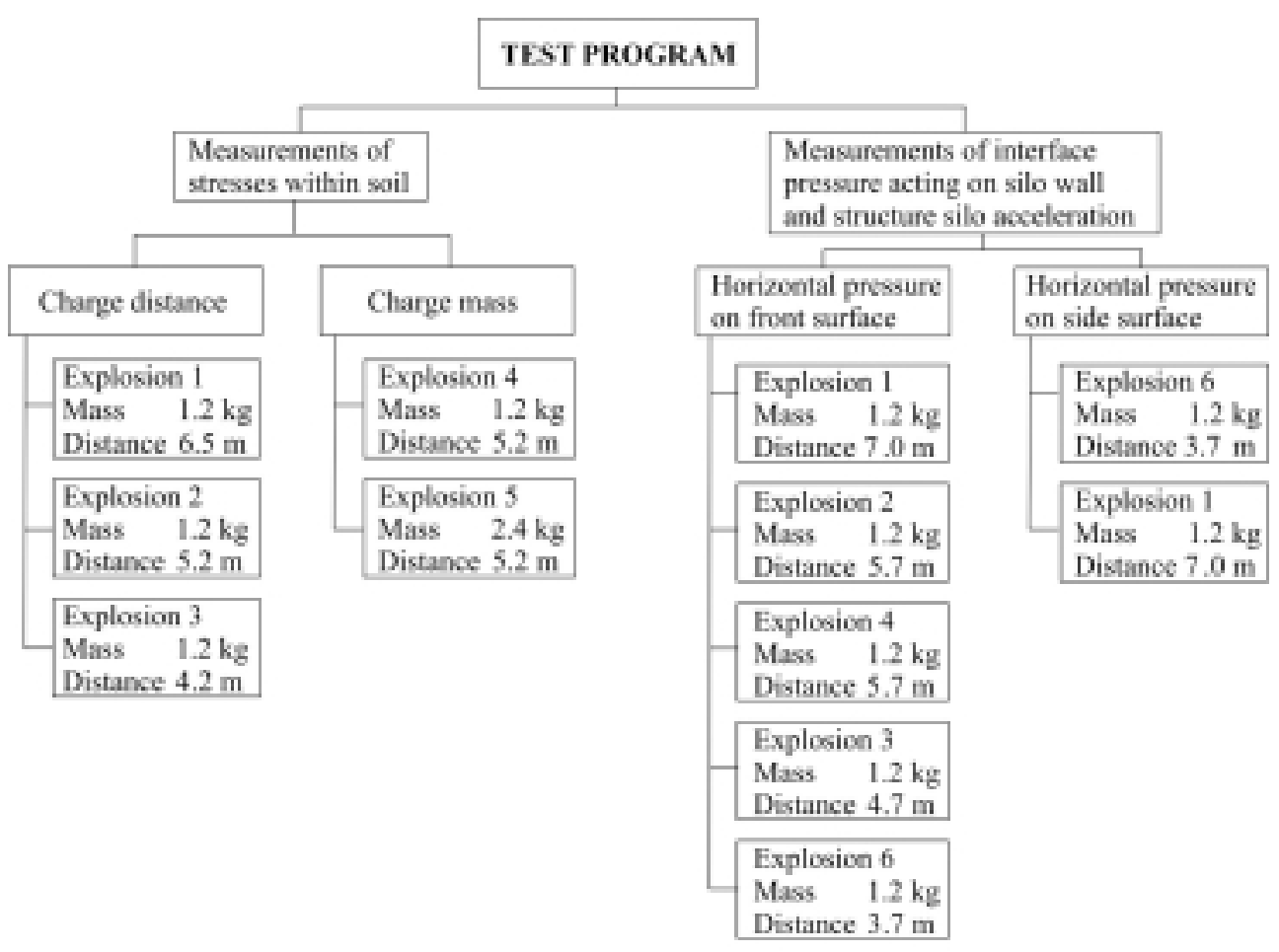

Depeh of charge placement $1.8 \mathrm{~m}$

$\frac{H}{D}-\frac{3.4}{1.25}-1.91$

Fig. 4. Test program.

holes were filled with the soil and compacted sensor placement. Attention was given during the sensor installation to precision of hole backfill and compaction around the stress gages to reproduce the in situ physical properties of virgin soil [16]. 


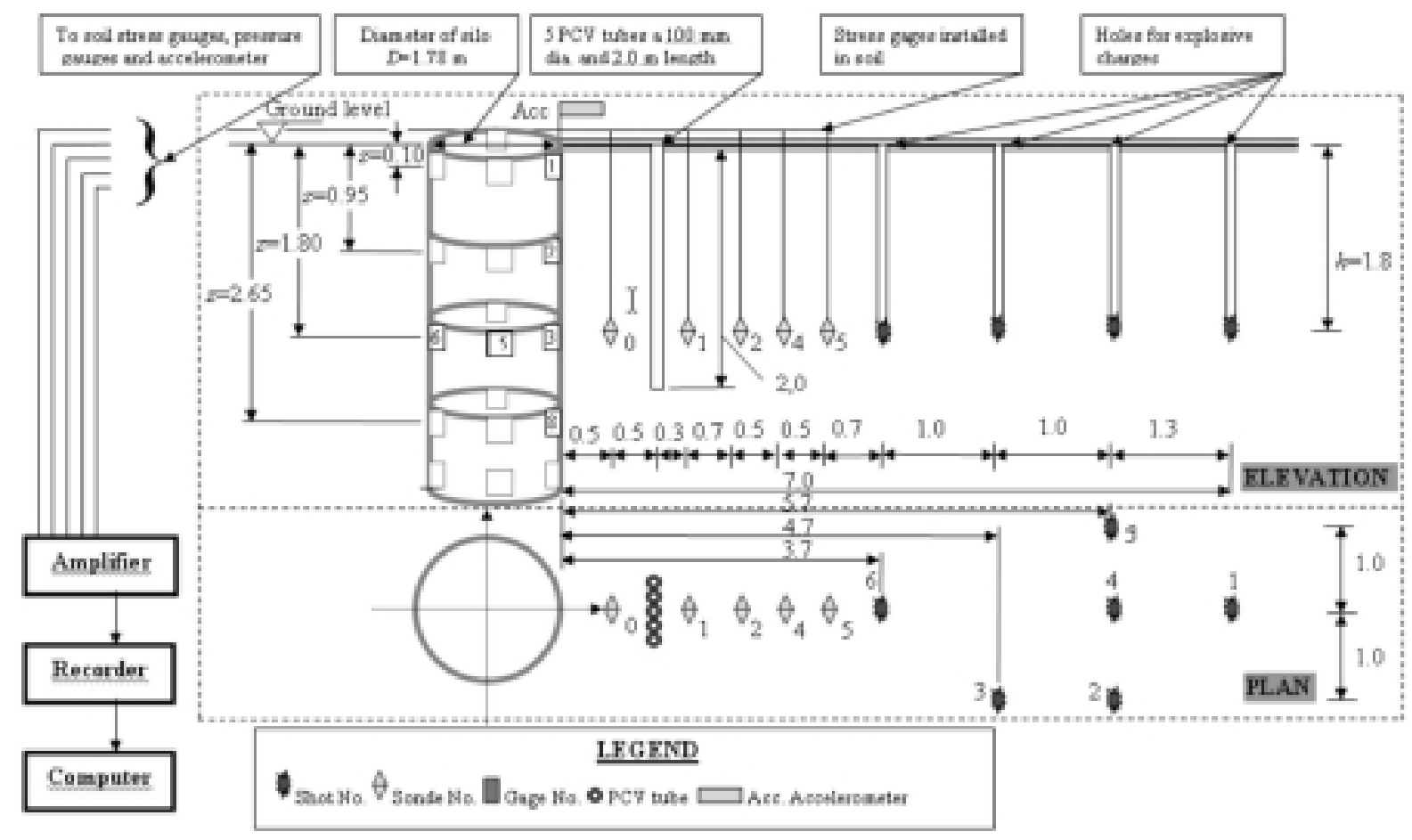

Fig. 5. Sequence of explosions and arrangements of soil stress gages and soil pressure gages.
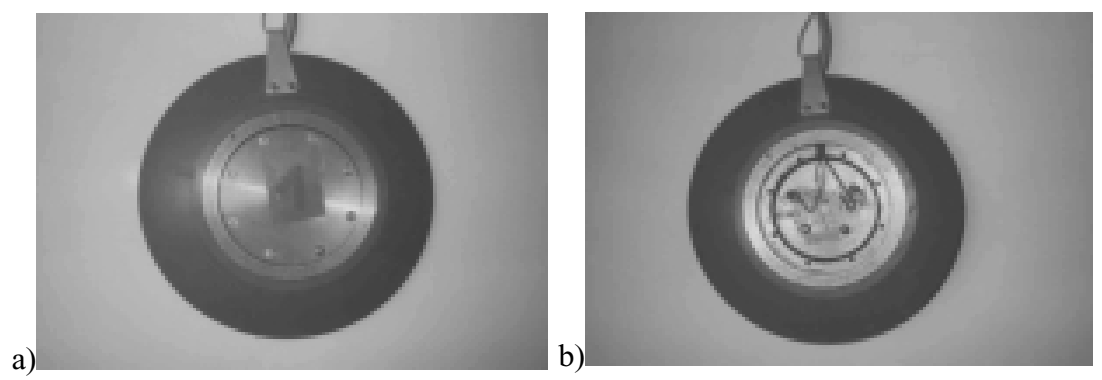

Fig. 6. Soil stress gage of diaphragm type with epoxy ring around its perimeter and rope to its suspension: a) view of gage with the plate fixed to the gage casing, b) cavity in casing and diaphragm instrumented with semiconductor strain gages.

Figure 7 shows three soil stresses-time histories measured by Gage No. 0, as a function of the distance from the detonated charge (charge placement depth $1.8 \mathrm{~m}$ ) with the barrier present. It should be emphasized that first charge was detonated at the farthest location from the soil stress gage, and the charges were gradually placed closer in subsequent tests. Therefore, the soil was undisturbed (virgin) only during the first test i.e. for the largest distance. The wave speed was the largest for the undisturbed soil, and it decreased in subsequent explosions, as observed from Fig. 7 where the arrival wave times from the explosion sources to soil stress gages are denoted. The calculated wave speed (distance divided by arrival time) for the first, second, and third explosions are $38.7 \mathrm{~m} / \mathrm{sec}, 24.5 \mathrm{~m} / \mathrm{sec}$ and $23.3 \mathrm{~m} / \mathrm{sec}$, respectively.

Figure 8 presents two soil stress-time histories for the charge masses of $1.2 \mathrm{~kg}$ and $2.4 \mathrm{~kg}$ with the barrier present. The charge-to-gage distance was $5.2 \mathrm{~m}$. As can be seen, the stress peaks are $2.51 \mathrm{kPa}$ and $4.34 \mathrm{kPa}$, respectively. In other tests with the detonation of the same charge mass and $4.4 \mathrm{~m}$ distance but without a barrier, the peaks stress measured by sonde No. 1 (placed before barrier) are larger and equal to $5.0 \mathrm{kPa}$ and $7.79 \mathrm{kPa}$, respectively. 


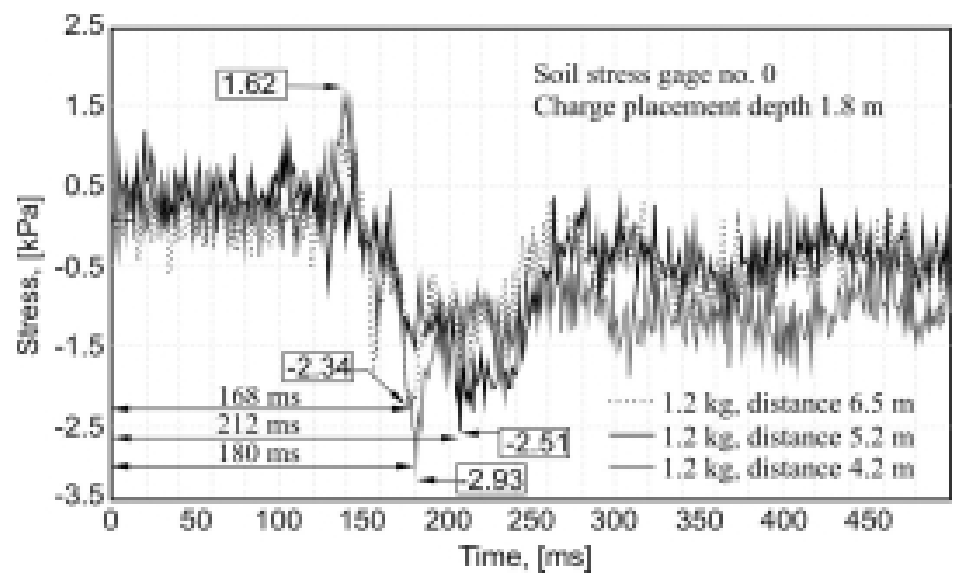

Fig. 7. Time history of normal soil stress $\sigma_{h}$ measured by gage No. 0 with the barrier.

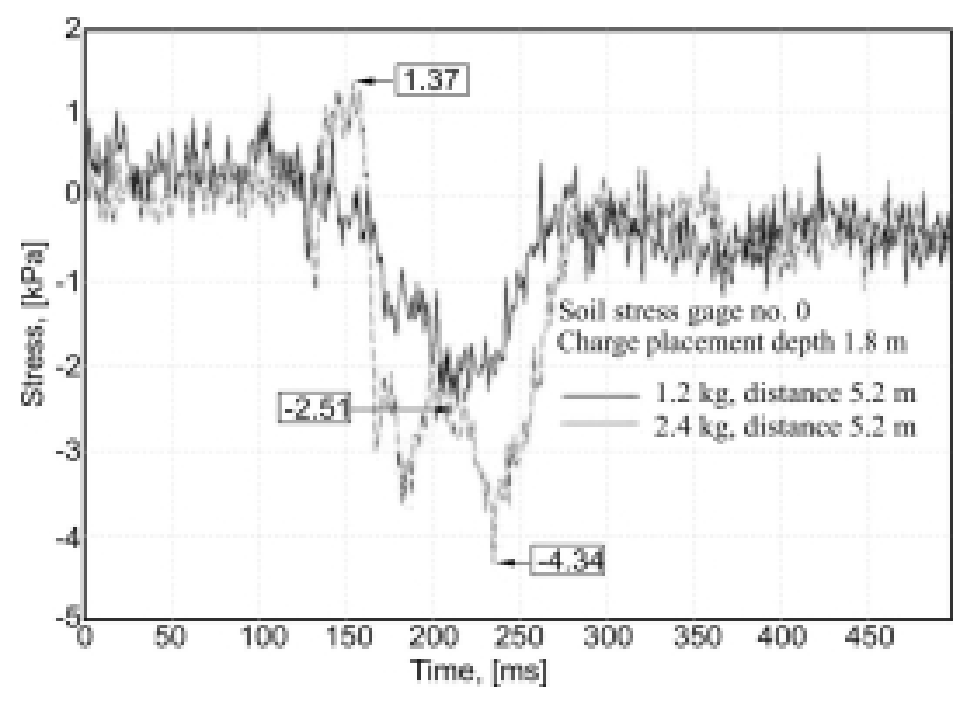

Fig. 8. Soil stress time histories $\sigma_{h}$ measured by gage No. 0 with the barrier.

\section{Pressures acting on an embedded silo structure in soil}

Figures 10 to 20 present the normal pressure-time histories induced on the structure, measured by pressure gages installed on the wall surface of the front, rear, and side generatrixes and, for various charge-to-structure distances, with and without an attenuation barrier (screen). Figure 10 shows a comparison between the pressure on the wall recorded by gage No. 1, without a barrier in the path of the propagating shock wave with that for the case with a barrier placed $1.0 \mathrm{~m}$ before the front of the silo wall. The barrier is marked on the figures by a vertical line to the left of the silo. This comparison shows very clearly that for a detonation at a distance of $7.0 \mathrm{~m}$ the attenuation barrier reduced the magnitude of the recorded peak interface pressure by more that $75 \%$, from about $6.1 \mathrm{kPa}$ to about $1.5 \mathrm{kPa}([6.1-1.5] / 6.1] \times 100 \%)$.

An assessment of the barrier's influence may be obtained by an attenuation coefficient $C_{t}$, as shown in Eq. (4):

$$
C_{t}=\frac{p_{h b}}{p_{h f}}
$$

In which, $p_{h b}$ is the interface pressure on the structure wall with the barrier (attenuated pressure), and $p_{h f}$ is the interface pressure on the wall without a barrier (free field or not-attenuated pressure). 


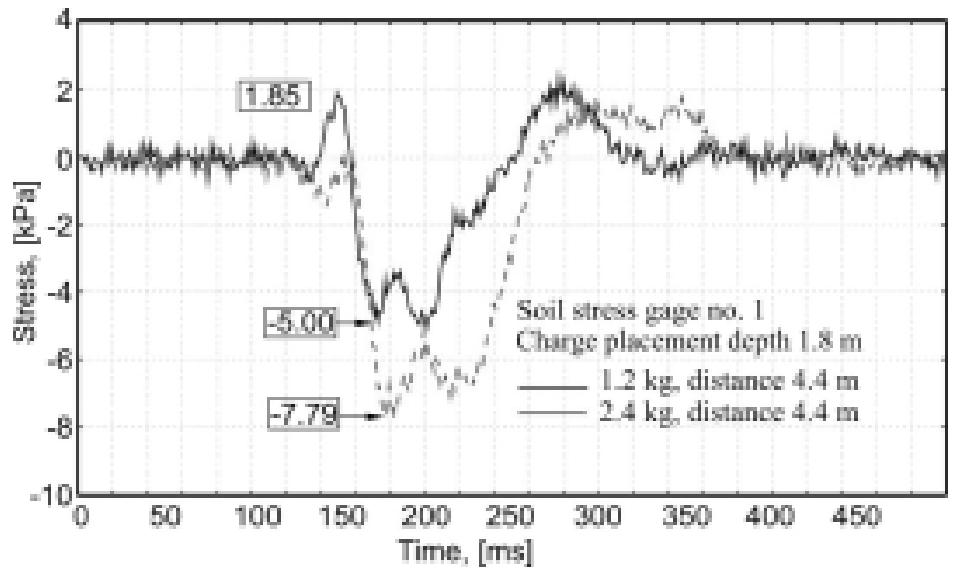

Fig. 9. Soil stress time histories $\sigma_{h}$ measured by gage No. 1 with the barrier behind.

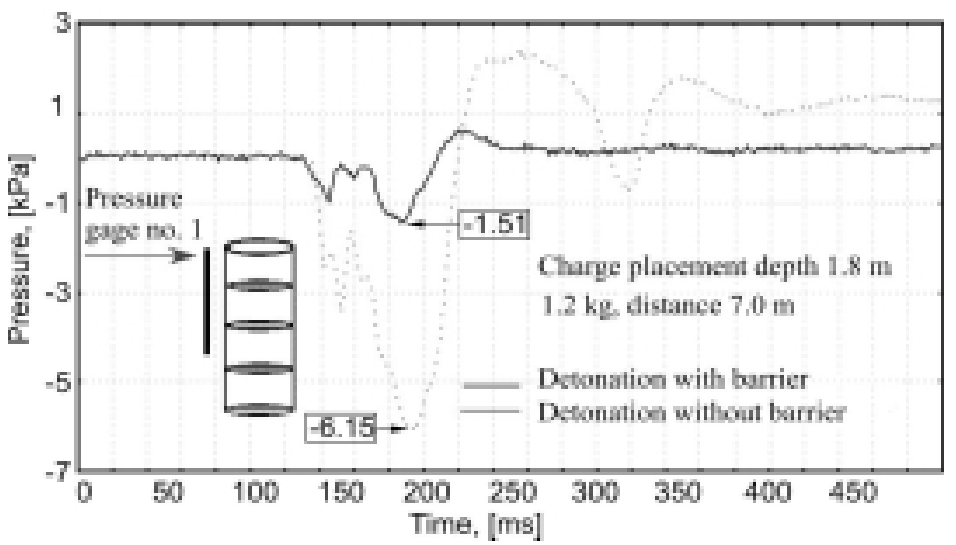

Fig. 10. Time histories of pressures $p_{h}$ on the structure front, measured by Gage No. 1 from a detonation at $7.0 \mathrm{~m}$ from the silo.

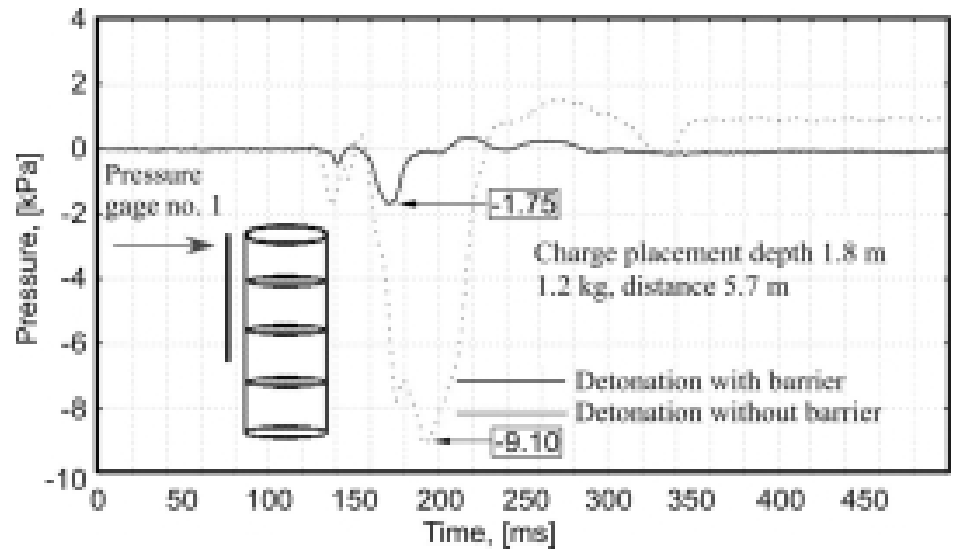

Fig. 11. Time histories of pressures $p_{h}$ on the structure front, measured by gage No. 1 from a detonation at $5.7 \mathrm{~m}$ from the silo.

The data registered by pressure gage No. 1 at the top of the front structure (Figs $10 \div 13$ ), indicate that the attenuation coefficients $C_{t}$, obtained from Eq. (4), for the distances $7.0 \mathrm{~m}, 5.7 \mathrm{~m}, 4.7 \mathrm{~m}$, and $3.7 \mathrm{~m}$ are equal to $0.23,0.19,0.52$, and 0.78 , respectively. As can be seen, the coefficients for distances of $7.0 \mathrm{~m}$ (shot No. 1) and 


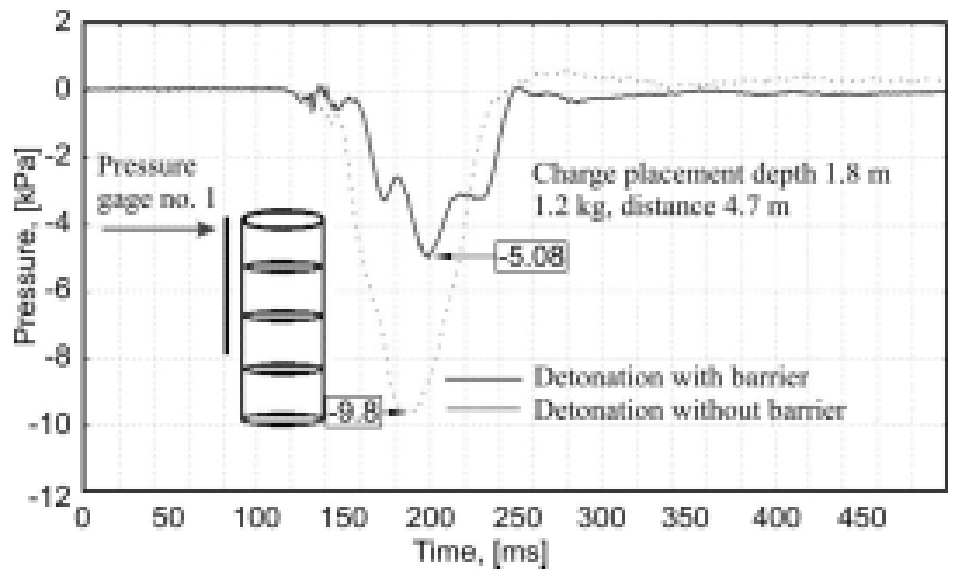

Fig. 12. Time histories of pressures $p_{h}$ on the structure front, measured by gage No. 1 from a detonation at $4.7 \mathrm{~m}$ from the silo.

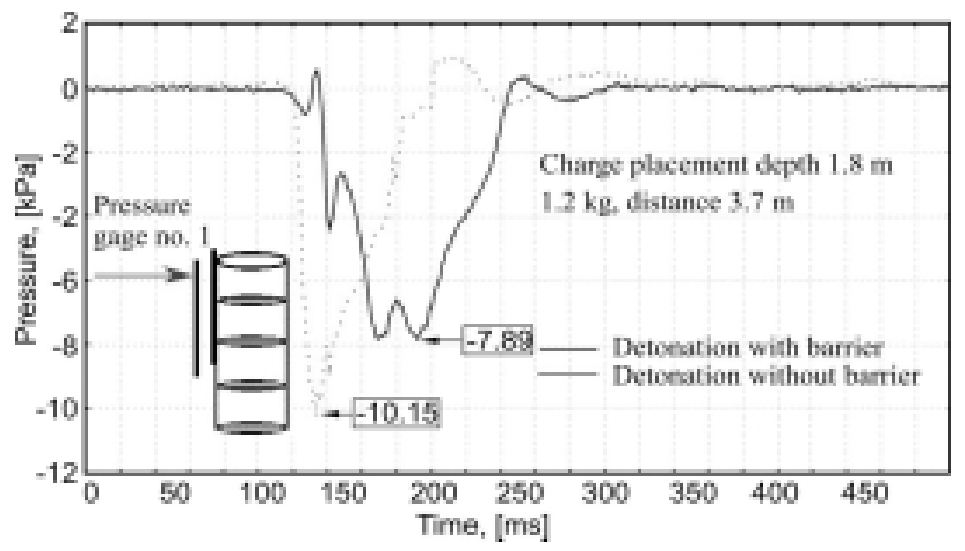

Fig. 13. Time histories of pressures $p_{h}$ on the structure front, measured by gage No. 1 from a detonation at $3.7 \mathrm{~m}$ from the silo.

$5.7 \mathrm{~m}$ (shot No. 4) are considerably smaller than for $4.7 \mathrm{~m}$ (shot No. 3) and $3.7 \mathrm{~m}$ (shot No. 6), and are related to the changes of soil properties in successive tests. As it was mentioned above, the soil was undisturbed only for the first detonation i.e. of $7.0 \mathrm{~m}$ distance. During successive detonations i.e. from $5.7 \mathrm{~m}, 4.7 \mathrm{~m}$ and $3.7 \mathrm{~m}$, the soil was more and more disturbed. This was especially true for shot No. 5 with a $2.4 \mathrm{~kg}$ charge, which totally destroyed the soil structure. The soil pressures acting on pressure gage No. 1 are caused mainly by surface waves, the soil destruction does not have much influence on pressure gage indications, as for pressure gage No. 2 that was placed at the mid height of the barrier. The values of pressure attenuation coefficients determined from gage No. 2 for the distances of $7.0 \mathrm{~m}, 5.7 \mathrm{~m}, 4.7 \mathrm{~m}$, and $3.7 \mathrm{~m}$ (Figs $14 \div 17$ ) were $0.07,0.25,0.99$ and 0.49 , respectively. An attenuation coefficient of 0.99 for the distance of $4.7 \mathrm{~m}$ (shot No. 3) means that the installation place of gage No. 2 is not fully protected from the blast waves. The gradually increasing coefficient values $(0.07,0.25$ and 0.49$)$ mainly depend on the level of soil destruction by preceding blast waves. Of course, the first coefficient value of 0.07 can be accepted as a conclusive value of attenuation coefficient for the PVC tube barrier in virgin soil. At the level of gage No. 8 $(z / D=1.49)$, where for each distance of detonation noted above, the coefficients are 0.36 (Fig. 20), 0.33, 0.14 and 0.18 , respectively.

Figure 18 presents two pressure-time histories recorded by gage No. $6(z / D=1.01)$ placed on the rear structure surface, with and without an attenuation barrier during explosion of a $1.2 \mathrm{~kg}$ charge at a distance of $5.7 \mathrm{~m}$. In this case, the attenuation is small, in spite of that this part of structure is screened by the barrier and soil is no so much destructed by only one previous detonation; the attenuated pressure was $4.26 \mathrm{kPa}$ vs. the unattenuated pressure of 


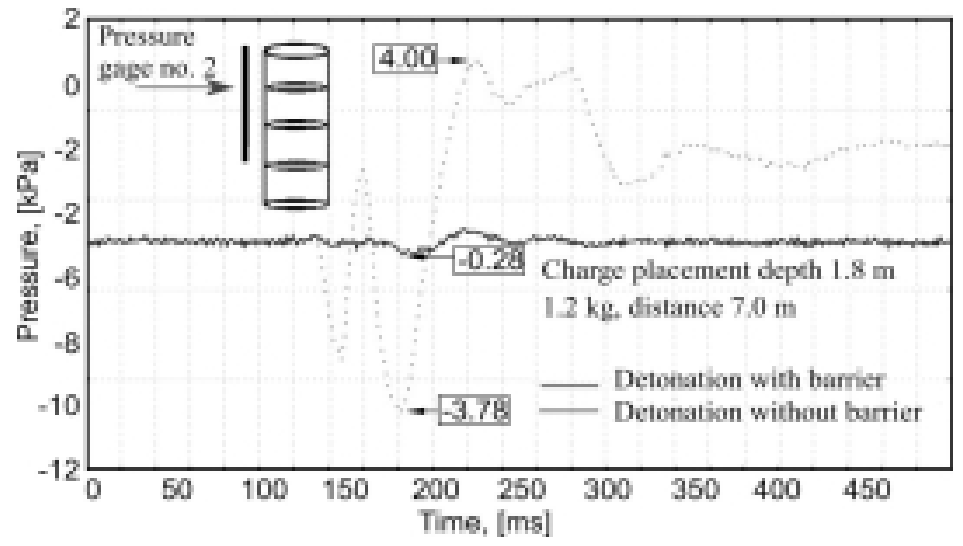

Fig. 14. Time histories of pressures $p_{h}$ on the structure front, measured by gage No. 2 from a detonation at $7.0 \mathrm{~m}$ from the silo.

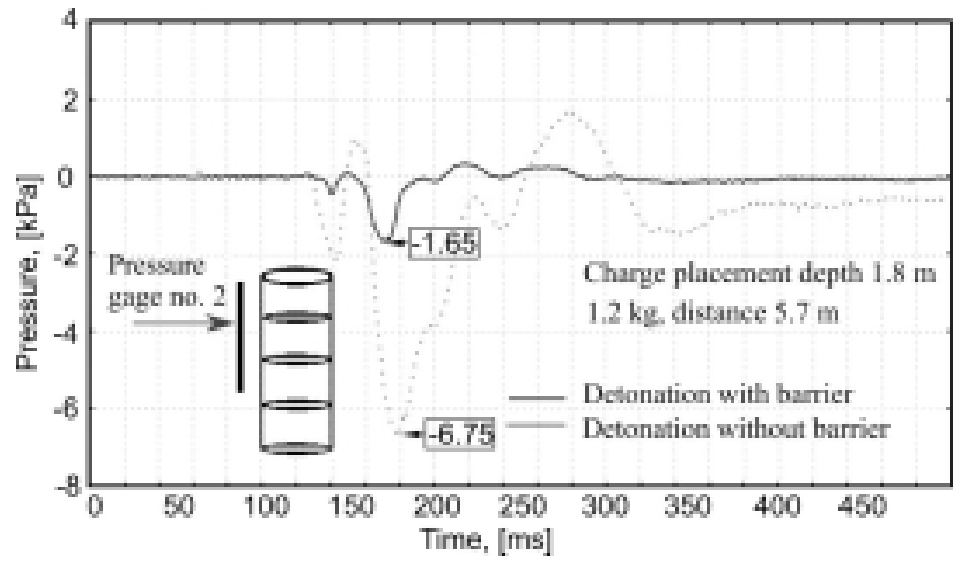

Fig. 15. Time histories of pressures $p_{h}$ on the structure front, measured by gage No. 2, from a detonation at $5.7 \mathrm{~m}$ from the silo.

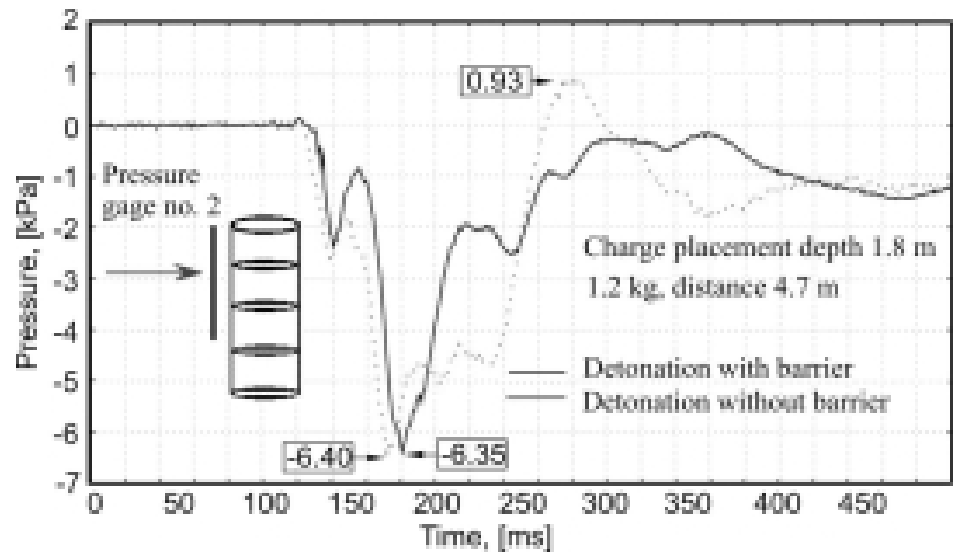

Fig. 16. Time histories of pressures $p_{h}$ on the structure front, measured by gage No. 2, from a detonation at $4.7 \mathrm{~m}$ from the silo.

$4.78 \mathrm{kPa}$. Similarly, the pressures registered by the gage No. 5 placed at the same depth $(z / D=1.01)$ on the side of the silo were $2.71 \mathrm{kPa}$ and $2.90 \mathrm{kPa}$ for the attenuated and unattenuated cases, respectively.

Comparatively, the high pressure attenuation $\left(C_{t}=0.36\right)$ was stated on level $z=2.65 \mathrm{~m}$ of gage No. 8 (Fig. 20), 


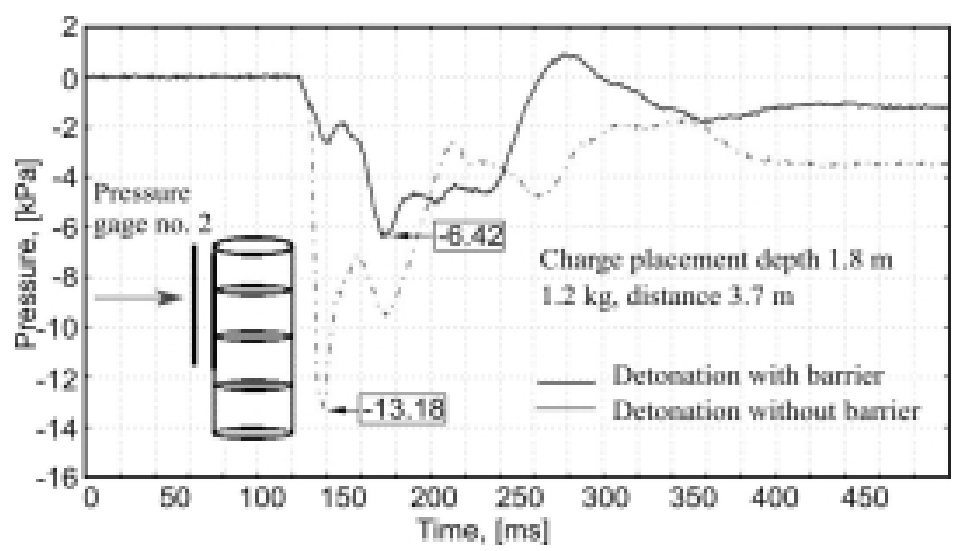

Fig. 17. Time histories of pressures $p_{h}$ on the structure front, measured by gage No. 2, from a detonation at $3.7 \mathrm{~m}$ from the silo.

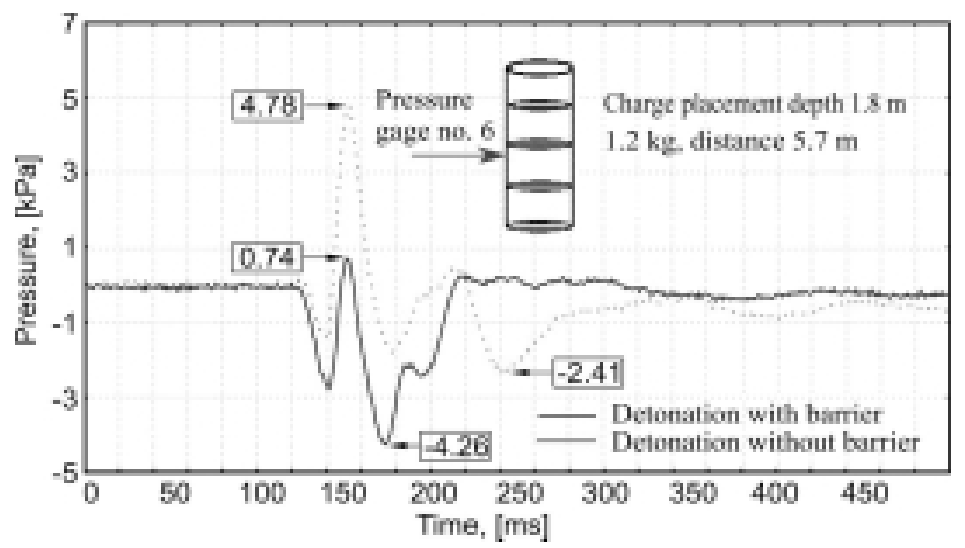

Fig. 18. Time histories of pressures $p_{h}$ acting on a structure rear, measured by gage No. 6 from a detonation at $5.7 \mathrm{~m}$ from the silo.

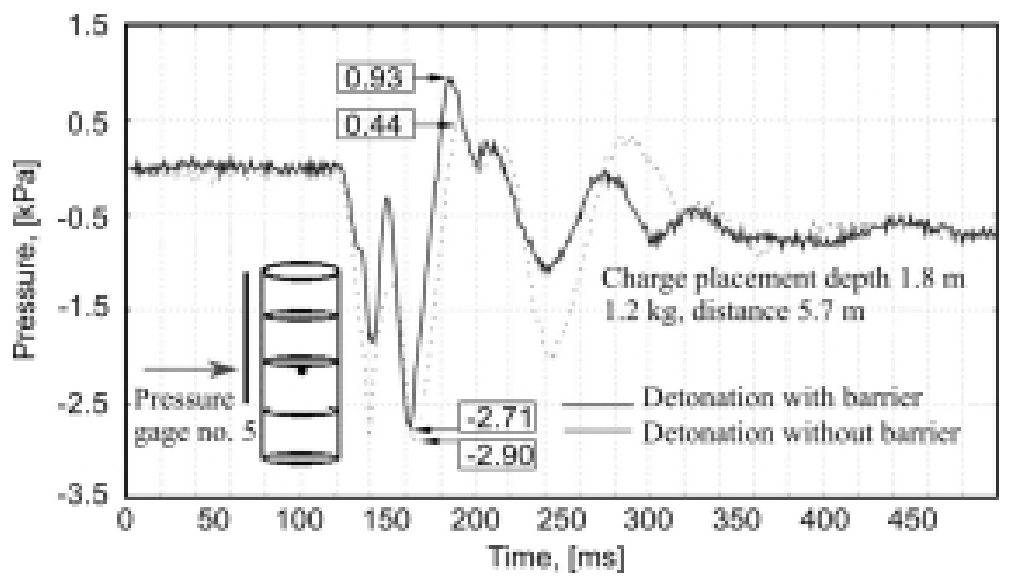

Fig. 19. Time histories of pressures $p_{h}$ acting on a structure side, measured by gage No. 5 from a detonation at $5.7 \mathrm{~m}$ from the silo.

which is below of the barrier. Significantly smaller pressure attenuation were obtained in the case screened gage placed on depth $z=1.80 \mathrm{~m}$. 


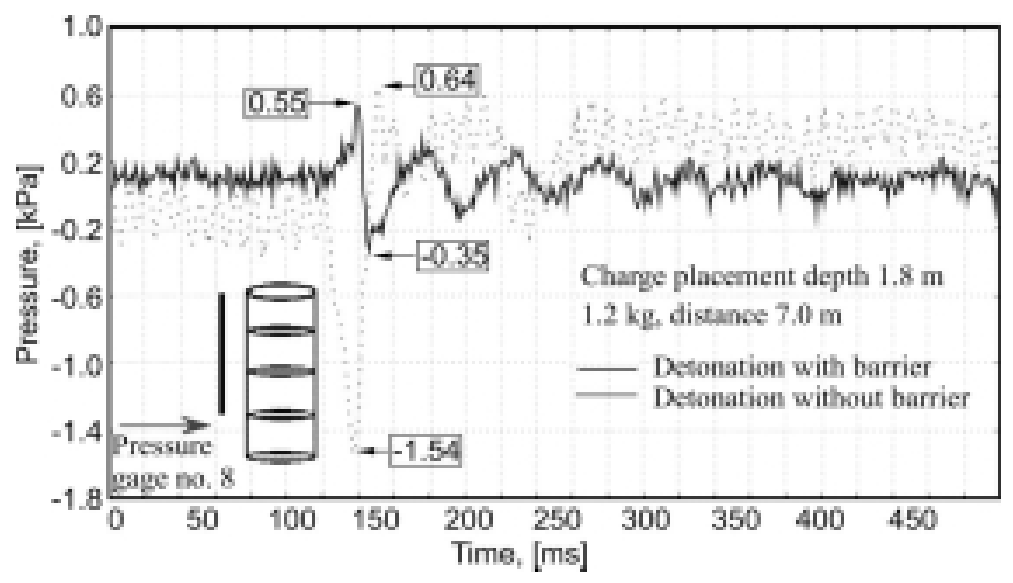

Fig. 20. Time histories of pressures $p_{h}$ on the structure front, measured by gage No. 8 from a detonation at $7.0 \mathrm{~m}$ from the silo.
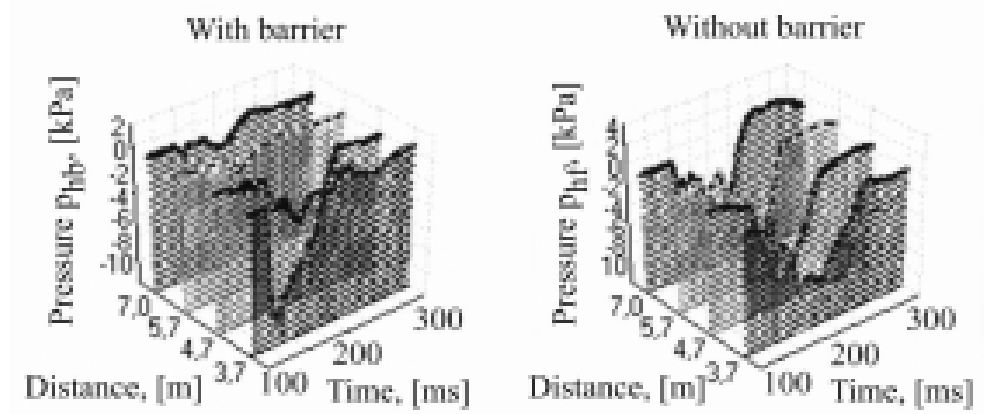

Fig. 21. Comparison of attenuated and unattenuated pressure trends vs. charge-structure distance at measurement depth of $0.10 \mathrm{~m}$ by gage No. 1 $(z / D=0.05)$.

\section{Analysis of interface pressure on a wall of a embedded silo with an attenuation barrier}

Figures 21, 22, and 23 show the attenuated and unattenuated horizontal soil pressures-time courses recorded by the gages placed on the silo front surface of numbers 1,2 and 8 at depths of $0.10 \mathrm{~m}, 0.95 \mathrm{~m}$, and $2.65 \mathrm{~m}$, respectively. These six figures (see different scales of pressures) show pressure-time histories caused by explosions of $1.2 \mathrm{~kg}$ mass charge from $7.0 \mathrm{~m}, 5.7 \mathrm{~m}, 4.7 \mathrm{~m}$ and $3.7 \mathrm{~m}$, respectively. As can be see from Figs 21, 22, and 23 that address the distance effect of pressures recorded by gages No. 1, No. 2, and No. 8, the general shape of the curves in the case of an explosion with a barrier for the largest distance i.e. $7.0 \mathrm{~m}$ (undisturbed soil) is like a ditch, and for the shortest distance of $3.7 \mathrm{~m}$ (disturbed soil) is like a valley. The depth of the ditches and the valleys correspond to pressure changes caused by charge explosions. As was mentioned earlier, the pressure traces for the largest distance of $7.0 \mathrm{~m}$, and also with some reservation for $5.7 \mathrm{~m}$, can taken as obtained for natural (undisturbed) soil conditions.

Figure 24 shows the maximum pressure parameter $\psi$ with and without attenuation along the height vs. the explosion distance parameter $\pi_{1}$. The values of $\pi_{1}$ and the corresponding ranges for $R$ were, as follows: 3.93 for $7.0 \mathrm{~m}, 3.20$ for $5.70 \mathrm{~m}, 2.64$ for $4.7 \mathrm{~m}$, and 2.07 for $3.7 \mathrm{~m}$. This comparison of the horizontal pressure coefficients with and without attenuation indicates very clearly that the pressure decreased during attenuation with all other conditions unchanged. But one should remember that the soil conditions in successive detonations from 1 to 6 deteriorated, and resulted in higher pressures on the silo wall than in the case of undisturbed soil.

As may be seen in Fig. 25, the smallest attenuation value corresponds to the case when the explosion occurs at the smallest distance from the barrier $\left(\pi_{1}=R / D=2,07\right)$. Also one can notice two different attenuation trends: one for $\pi_{1}$ of 3.93 and 3.20, and the second for $\pi_{1}$ of 2.67, and 2.07. In the first case i.e. for longer charge-to-silo distance it shows an equal barrier influence along the silo height with no changed soil properties, and in the second 

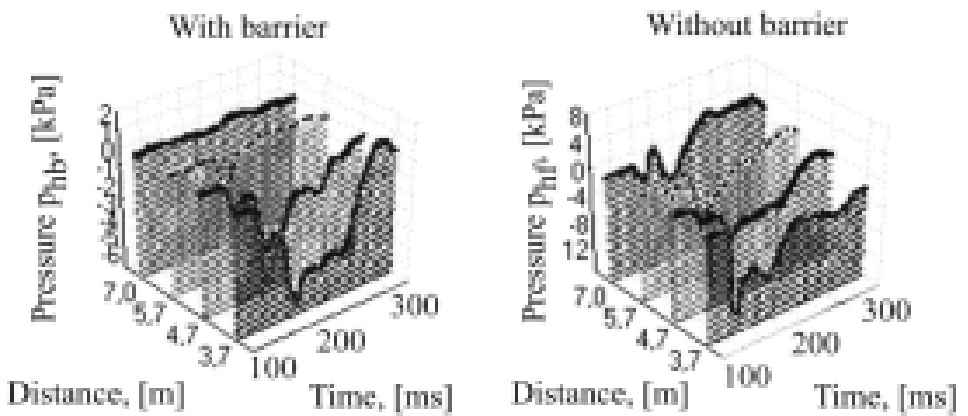

Fig. 22. Comparison of attenuated and unattenuated pressure trends vs. charge-structure distance at measurement depth of $0.95 \mathrm{~m}$ by gage no. 2 $(z / D=0.53)$
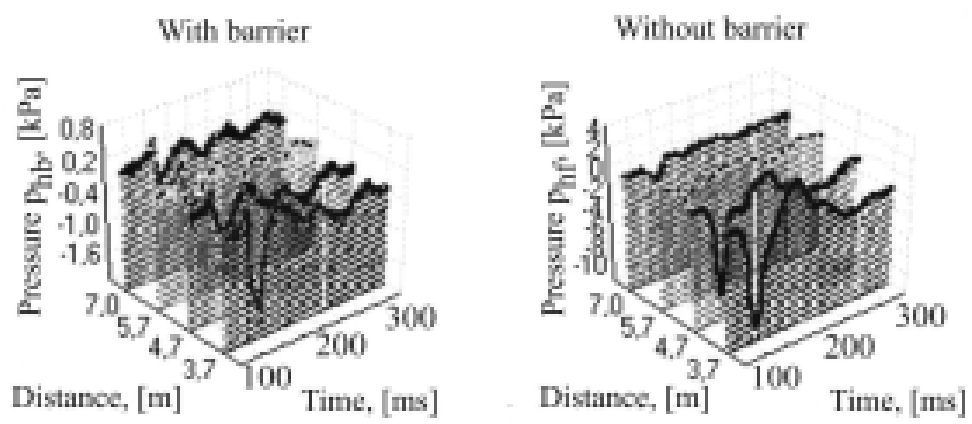

Fig. 23. Comparison of attenuated and unattenuated pressure trends vs. charge-structure distance at measurement depth of $2.65 \mathrm{~m}$ by gage no. 8 $(z / D=1.01)$

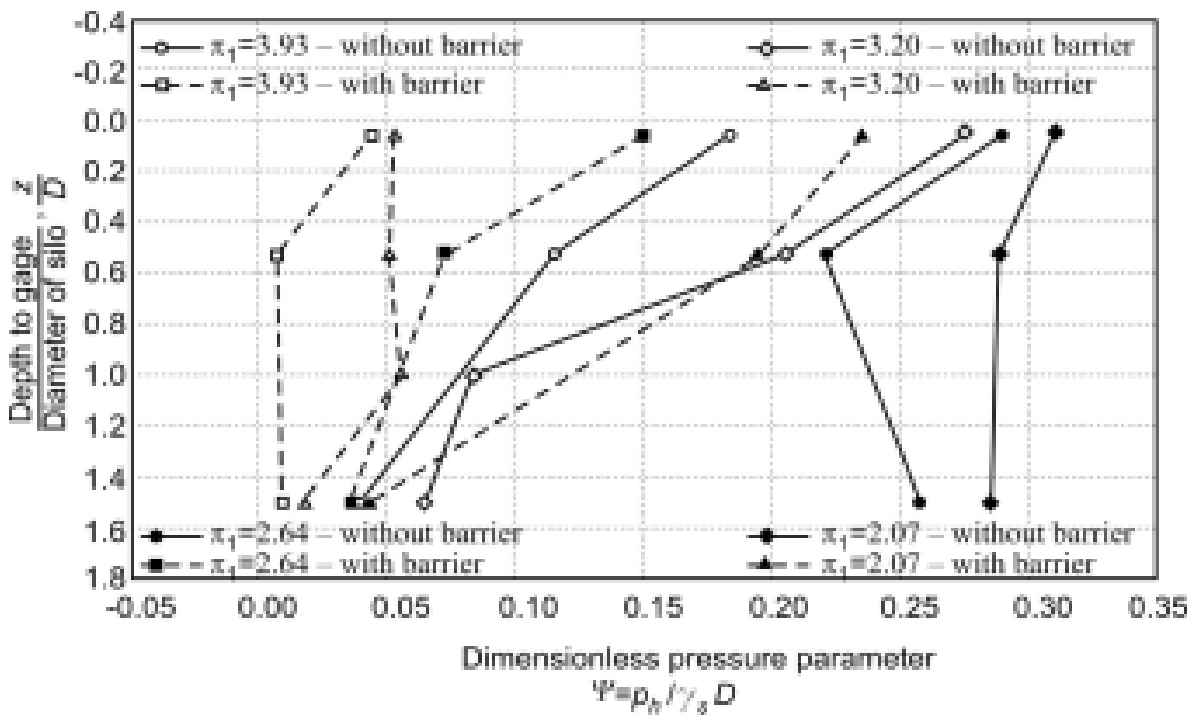

Fig. 24. Comparison of the horizontal pressure coefficient acting on the front of the wall with and without attenuation, as a function of $\pi=R / D$ for $\pi_{3}=1.01$ and $\pi_{6}=4.0 \cdot 10^{-4}$.

case i.e. for smaller charge-to-silo distance one can observe the best attenuation on the silo bottom and a poor barrier influence on the silo top, especially for $\pi_{1}=2.07$ with some influence of soil destruction caused by successive 


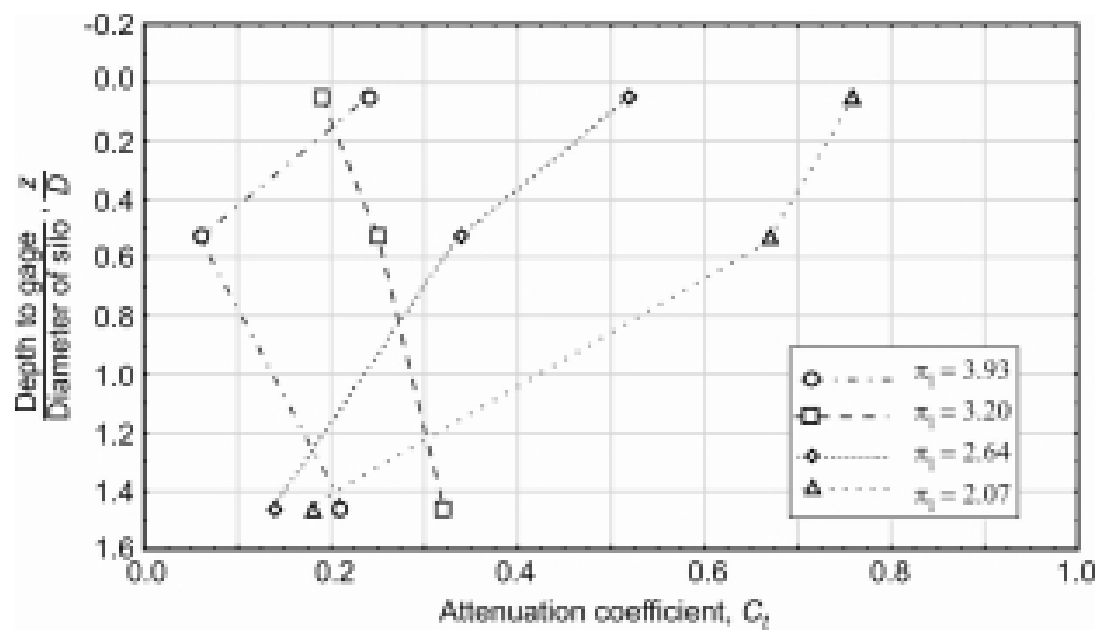

Fig. 25. Attenuation coefficient at different detonation distances for $\pi_{B}=1.01$ along the height of front silo.

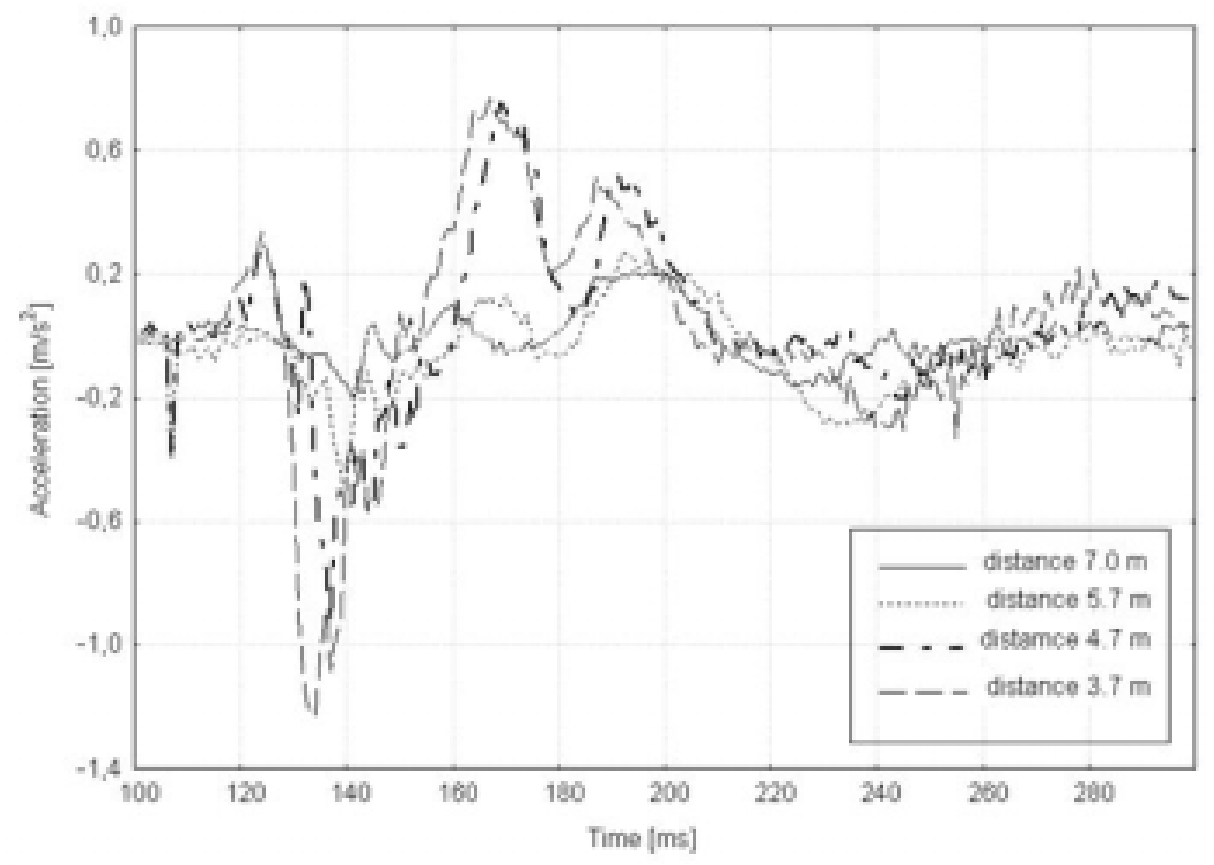

Fig. 26. Time histories of structure acceleration depend on detonation distance charge-silo without barrier.

explosions.

The relationships between the structure accelerations and the various parameters were also studied, as shown in Fig. 26 (unattenuated), 27 (attenuated), and 28 (comparisons between the two).

Figures 26 and 27 show the relationship between acceleration and detonation distance with and without the barrier present, respectively. One can note that the structure's accelerations is larger for shorter charge-to-silo distances. Of course, structural accelerations values are larger without a barrier. One may conclude that for longer distances the acceleration is unaffected by a barrier. It can be clearly noted from Fig. 28 that the barrier affects the acceleration for charge distance of less than $5.7 \mathrm{~m}$, while it has no effect for larger charge distances. 


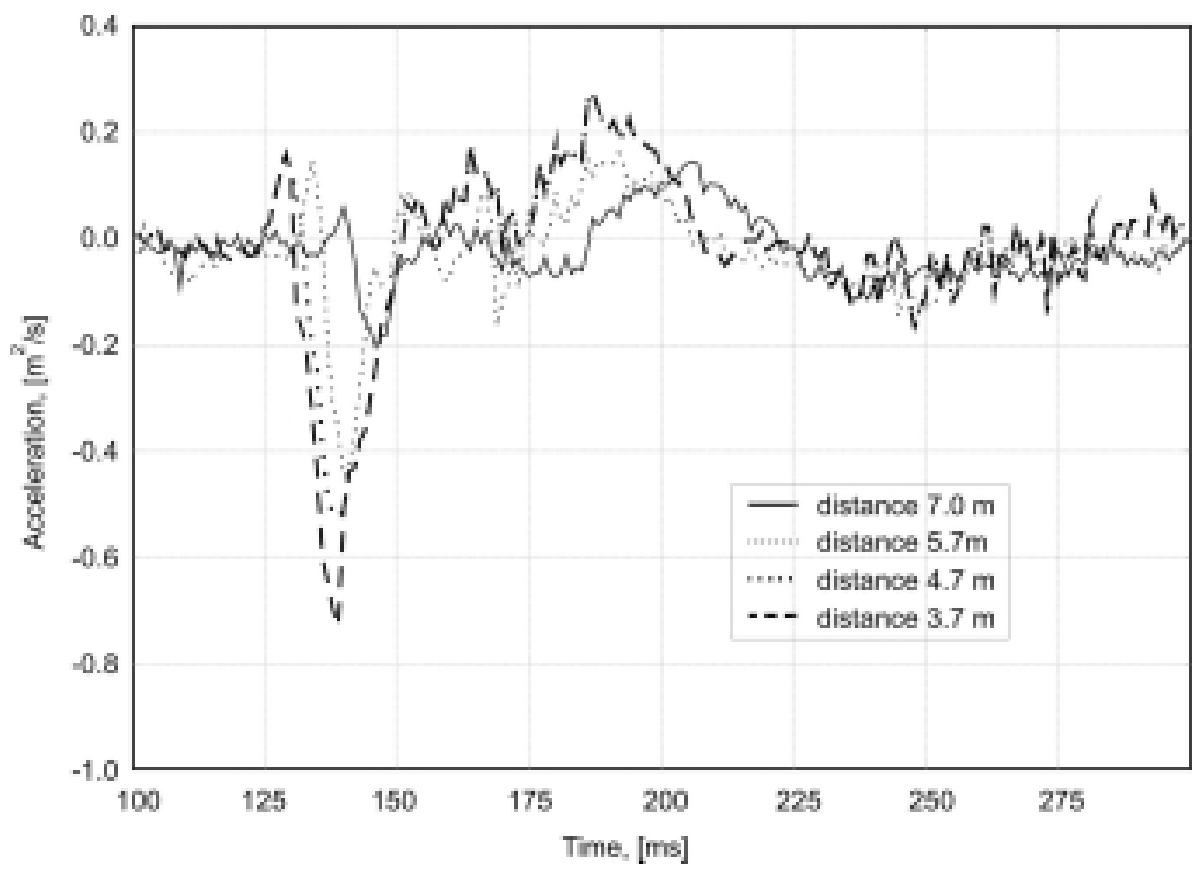

Fig. 27. Time histories of structure acceleration depend on detonation distance charge-silo with barrier.

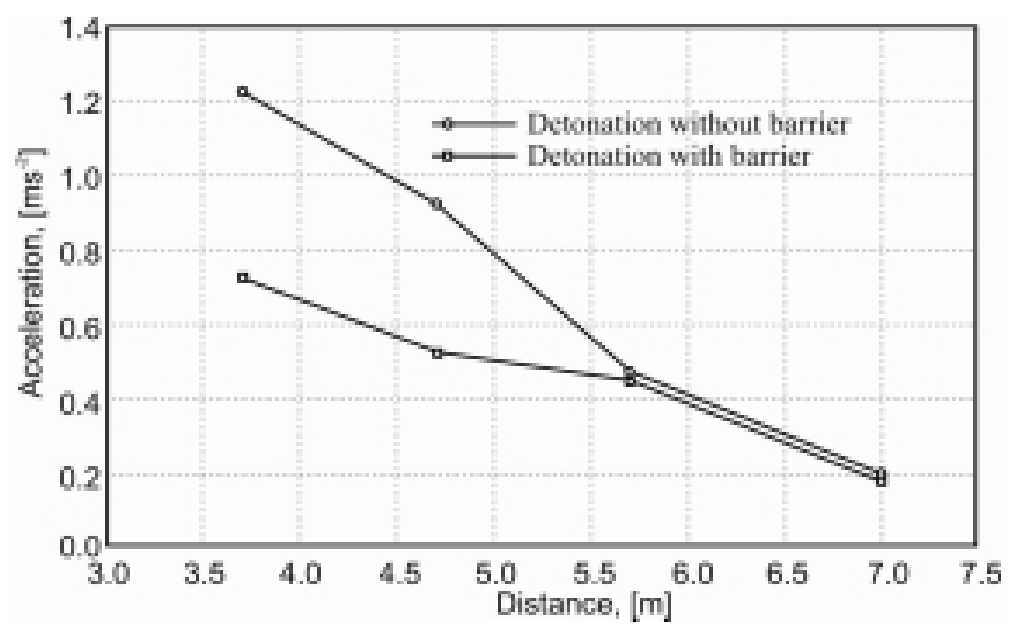

Fig. 28. Barrier influence on structural accelerations vs. charge-to-structure distance.

\section{Conclusions}

The following conclusions were obtained based on the findings from this pilot study:

1) The effectiveness of the attenuation barrier in regard to pressure reduction increased with the increased distance between the explosion source and the silo, when the structure-to-barrier distance was unchanged.

2) The barrier is ineffective in shielding the upper part of the structure when the explosion occurs very close to the barrier. However, the barrier can shield the structure only if its strength is sufficient, and it will not fail under the incoming ground shock But one should take under consideration the destruction of the soil by previous explosions. 
3) It was noted that very high pressures (i.e., small attenuation) were registered by the gages placed on the side $\left(C_{t}=0.93\right)$ and rear $\left(C_{t}=0.89\right)$ of the silo surface at mid height $(z / D=1.01)$.

4) The structural acceleration increased with increased charge weight and detonation depth.

5) Additional studies are required to obtain more complete explanations of these phenomena. For example, to consider the effects of different soil conditions (e.g., others soil profiles), a broader range of structural and barrier dimensions, relative structure-to-barrier locations, charge sizes, and detonation depths and charge-tostructure distances. Because the detonations change the native soil properties, the soil should be restored in each successive tests.

\section{Acknowledgements}

The research described in this paper was conducted at the College of Military Engineering, Wroclaw, and was jointly supported by CME and grant No. 7 T07E 04910 from the Scientific Research Committee, Warsaw. This support is gratefully acknowledged.

\section{References}

[1] S. Ahmad and T.M. Al-Hussaini, Simplified design for vibration screening by open and in-filled trenches, ASCE Journal of Geotechnical Engineering 117(1) (1991), 67-88.

[2] D.D. Barkan, Dynamics of Bases and Foundations, MacGraw-Hill Book Company, Inc., 1962, 374-406.

[3] D.E. Beskos, B. Dasgupta and I.G. Vardoulakis, Vibration Isolation Using Open or Filled Trenches; Part 1: 3-D Homogeneous Soil, Computational Mech., 1990, No. 6, Springer, 43-63.

[4] D.E. Beskos, B. Dasgupta and I.G. Vardoulakis, Vibration Isolation Using Open or Filled Trenches; Part 2: 2-D Homogeneous Soil, Computational Mech. (1990), No. 6, Springer.

[5] S.F. Brown, State-of-the art on field instrumentation for pavement experiments, Record No. 640, Transp. Res. Board, $1977,13-28$.

[6] P.S. Bulson, Structures Under Shock and Impact, Buried Structures, Chapman and Hall, London, 1985, $202-211$.

[7] M. Das Braja, Fundamentals of Soil Dynamics, Elsevier. New York, Amsterdam, Oxford, 1983.

[8] M.C.R. Davies and A.J. Williams, Centrifuge modeling of the protection of buried structures, Report of the first phase of the study to Defense Research Agency (Christchurch), University of Wales, Cardiff, 1992.

[9] M.C.R. Davies and A.B. Ismail, Retro-fitting of expedient protection for buried structures, in: Rapidly Assembled Structures, P.S. Bulson, ed., Proc. Int. Conf. on Mobile stabilisierte Schlitz, VDI Bericht Nr 88, 1965.

[10] W.A. Haupt, Behaviour of surface waves in homogeneous halfspace with special consideration of wave isolation, Doctoral Thesis, Univ. of Karlsruhe (74) (1978), 84-94.

[11] W.A. Haupt, Wave Propagation in the Ground and Isolation Measures, (Vol. 3), Proceedings, $3^{\text {rd }}$ Int. Conference on Recent Advances in Geotechnical Earthquake Engineering and Soil Dynamics, St. Louis, Missouri, State-of-the-Art Paper, 1995, 985-1016.

[12] K.A. Jackura, Instruments for Determining Stress-Displacement in Soils, Calif. State Dept. Transportation, Rep. No. FHWA/CA/TL-81/09, July 1981.

[13] S. Kobielak and T. Krauthammer, Dynamic response of buried silo caused by underground explosion, Shock and Vibration 11(5,6) (2004), 665-684.

[14] K.R. Massarsch, Man-made vibrations and solutions, State-of-the-Art Lecture, Proceedings Third International Conference on Case Histories in Geotechnical Engineering, St. Louis, Missouri II (June 1-6) (1993), 1393-1405.

[15] K.R. Massarsch, Vibration Isolation Using Gas-Field Cushions, Keynote Lecture: Geofronties 2005 - International Conference, ASCE, Austin, Texas, January 24-26, 2005.

[16] G.E. Triandafilidis, Soil-stress gage design and evaluation, Journal of Testing and Evaluation 2(3) (1974), 146-158.

[17] A.J. Williams, M.C.R. Davies and N. Woodward, Centrifuge Modeling of the Protection of Buried Structures from Buried Explosives Using Different Barrier Mechanisms, 2nd Asia - Pacific Conference on Shock \& Impact Loads on Structures: Melbourne, Australia, November 25-27, 1997.

[18] R.D. Woods, Screening of surface waves in soils, Journal of the Soil Mechanics and Foundation Division, ASCE 94(SM4) (1968), 969,

[19] R.D. Woods, N.E. Barnett and R. Sagessar, Holography - New tool for soil dynamics, Journal of the Geotechnical Engineering Division, ASCE 100(GT11), 1240. 

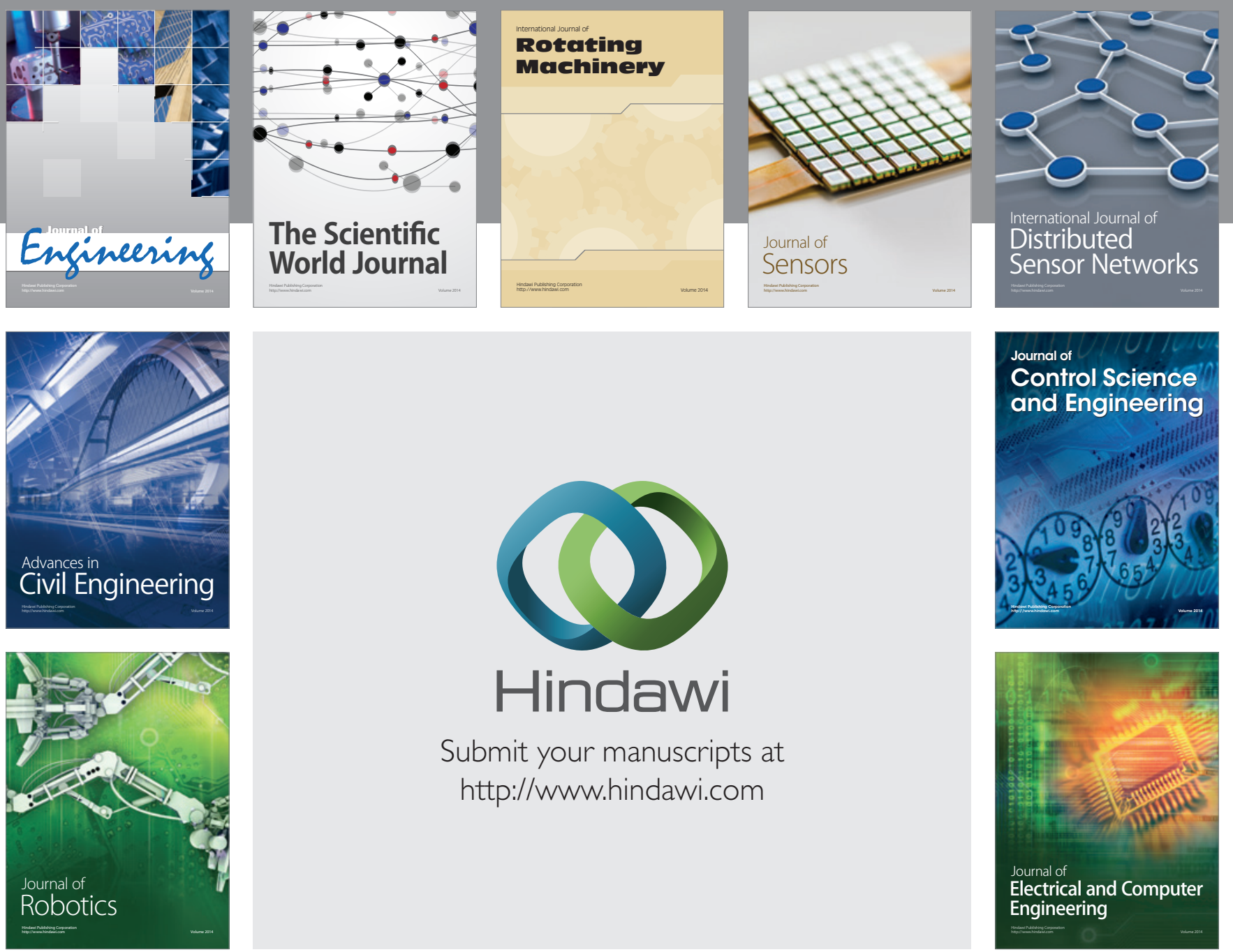

Submit your manuscripts at

http://www.hindawi.com
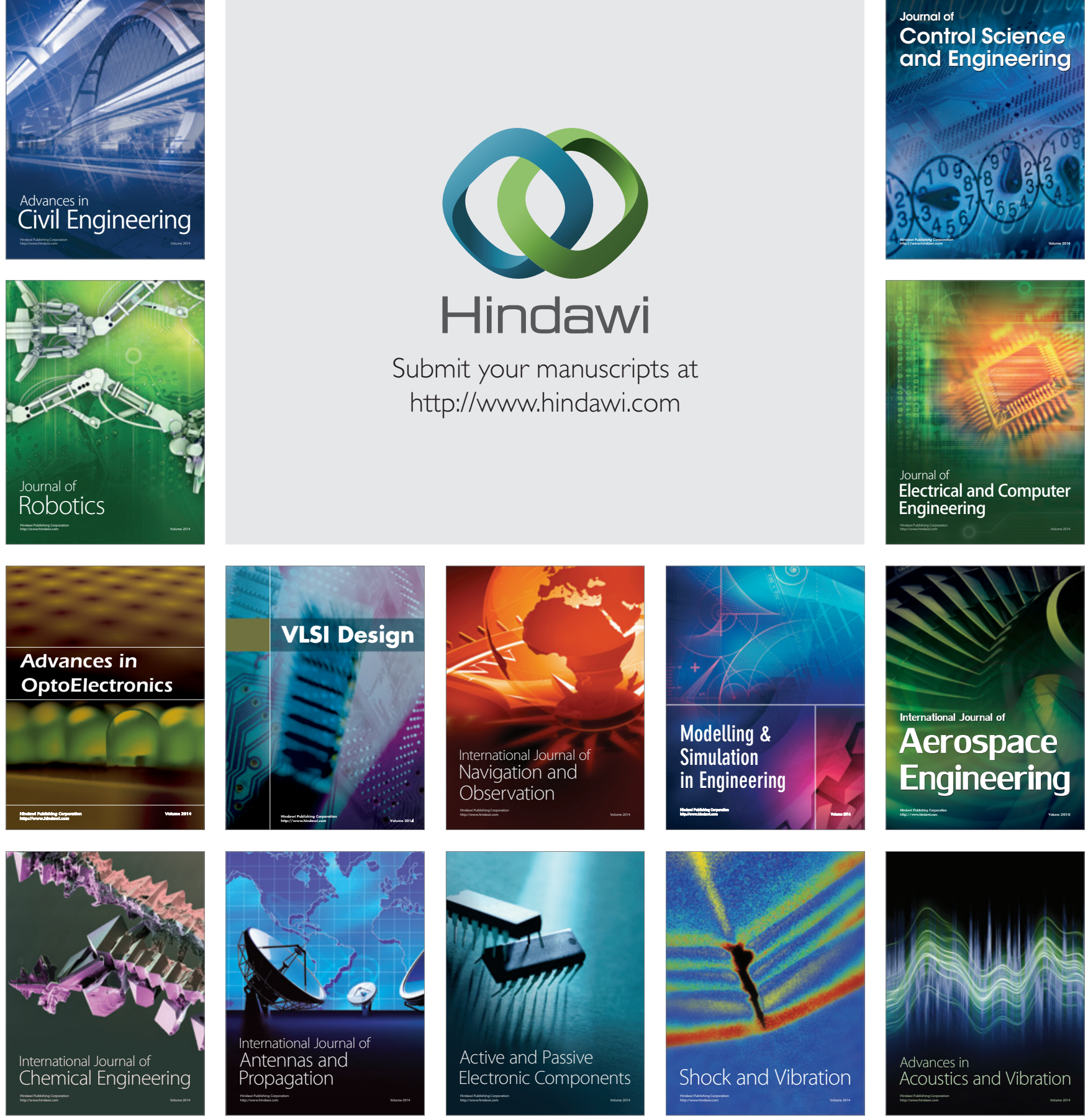